\title{
Room Temperature Storage of Hydrogen by Carbons
}

\author{
Mitsunori Furuya, Ayaka Yanagitsuru, Yuuya Matsuo, Kenji Ichimura \\ Graduate School of Science and Technology, Kumamoto University, Kumamoto, Japan \\ Email: ichimura@kumamoto-u.ac.jp
}

Received May 9, 2013; revised June 9, 2013; accepted July 9, 2013

Copyright (C) 2013 Mitsunori Furuya et al. This is an open access article distributed under the Creative Commons Attribution License, which permits unrestricted use, distribution, and reproduction in any medium, provided the original work is properly cited.

\begin{abstract}
The adsorption states of hydrogen at around $300 \mathrm{~K}$ are found on carbons by means of thermal desorption measurements. This sorption ability has utility for energy technologies such as fuel cells.
\end{abstract}

Keywords: Hydrogen; Storage; Carbon; Absorption States

\section{Introduction}

We have reported the chemical interactions of hydrogen in the solids $\mathrm{C}_{60}, \mathrm{Na}-\mathrm{C}_{60}-\mathrm{H}$ ternary systems (super-conducting (SC) and non-super-conducting non-SC Phases) and carbon nanotube [1-7], as shown in Figure 1.

This paper presents results in the thermal desorption of hydrogen from carbon blacks and carbon nanohorn.

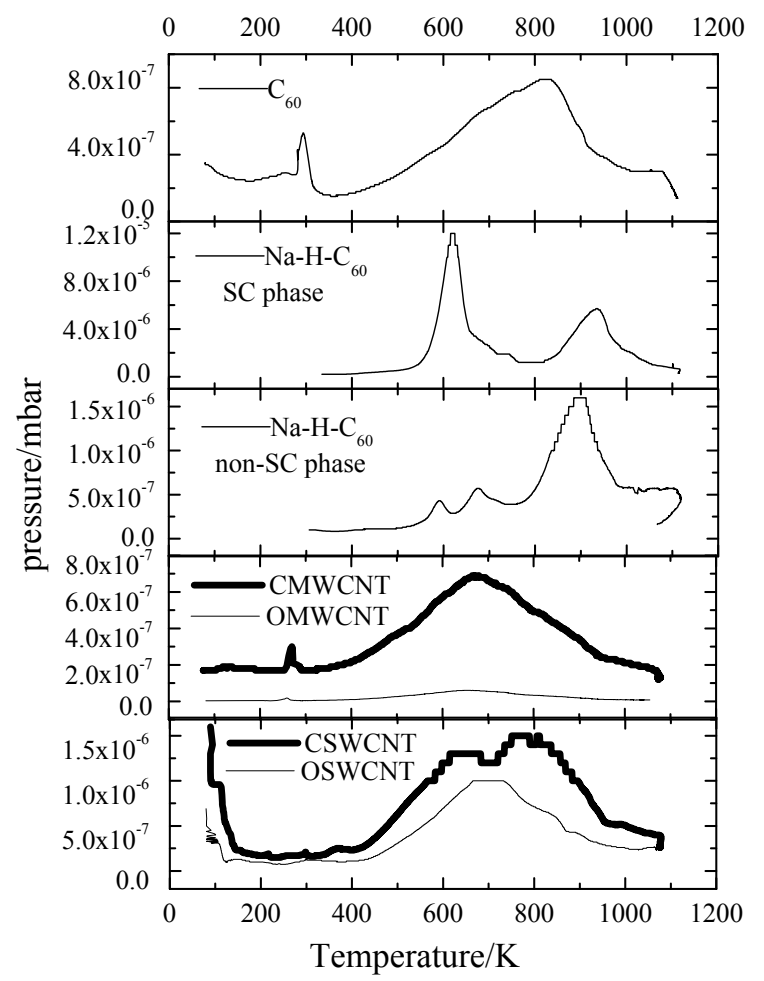

Figure 1. The thermal desorption of hydrogen from $C_{60}$, $\mathrm{Na}-\mathrm{H}-\mathrm{C}_{60}$ and carbon nanotubes.

\section{Experimental}

$\mathrm{C}_{60}$ (Hoechst, 99.98\% purity) was used without further purification.

The synthesis of $\mathrm{Na}_{\mathrm{x}} \mathrm{H}_{\mathrm{y}} \mathrm{C}_{60}$ was done as follows: The mixture of stoichiometric amounts of $\mathrm{NaH}$ and $\mathrm{C}_{60}$ powders was loaded in a quartz tube in a dry box filled with Ar gas. Then the sample in the tube sealed under the pressure of $\sim 10^{-4} \mathrm{~Pa}$ was heated at $553 \mathrm{~K}$ for $1 \mathrm{~h}$ in a muffle furnace.

Capped and open (no endcaps) single wall carbon nanotubes (CSWCNT and OSWCNT, Bucky USA BU202 (endcaps) and BU-203 (no endcaps), respectively, with 1.4 - $3 \mathrm{~nm}$ diameter and 10 - $50 \mu \mathrm{m}$ length) were used without further purification for the adsorption studies. The only difference between BU-202 and BU-203 is the endcap structure at both ends, and other- wise the two structures are the same.

Carbon black (Seast 3HAF) and graphitized carbon blacks (\#3855, \#3845 and \#3800) were supplied from Tokai Carbon Co. Table 1 shows the characterizaion of samples.

Carbon nanohorn was synthesized by means of the arcing method and supplied by Yamaguchi and Iijima $[8,9]$.

Table 1. Caracteristics of carbon blacks.

\begin{tabular}{cccc}
\hline sample & weight/mg & Particle radii/nm & $\begin{array}{c}\mathrm{N}_{2} \text { specific surface } \\
\text { area } / \mathrm{m}^{2} / \mathrm{g}\end{array}$ \\
\hline $\begin{array}{c}\text { Seast 3HAF } \\
\text { (S3) }\end{array}$ & 32 & 28 & 79 \\
$\# 3855$ & 32.2 & 25 & 90 \\
$\# 3845$ & 33.1 & 40 & 57 \\
$\# 3800$ & 32.1 & 70 & 27 \\
\hline
\end{tabular}


After vacuum heating at $653 \mathrm{~K}$ or $1073 \mathrm{~K}$, the samples were exposed to hydrogen (Nippon Sanso, $>99.9999 \%$ purity) 1 to $1.4 \mathrm{~atm}$, at $473 \mathrm{~K}$ for 3 - 5 days. After the sample was cooled to liquid nitrogen temperature, the sample tube was evacuated to ultra-high vacuum. Desorbed gas was analyzed by using two mass-spectrometers when the sample was heated at a temperature-rise rate of $5 \mathrm{~K} / \mathrm{min}$.

\section{Results and Discussion}

As shown in Figure 1, for $\mathrm{C}_{60}$ and carbon nanotubes, the desorption of hydrogen was observed below $300 \mathrm{~K}$. The temperature region of desorption below $300 \mathrm{~K}$ suggests the interaction by van der Waals and/or weak chemical bonding. The further desorption peaks were observed at around $820 \mathrm{~K}$ for $\mathrm{C}_{60}$ and $650 \mathrm{~K}$ for carbon nanotubes. The temperature region of desorption above $300 \mathrm{~K}$ suggests the interaction by strong chemical bonding. In the $\mathrm{KC}_{8} \mathrm{H}_{0.6}$ ternary system, the hydrogen desorption peak appears at $512 \mathrm{~K}$. The desorption peaks of hydrogen in $\mathrm{Na}-\mathrm{H}-\mathrm{C}_{60}$ appear at around $650 \mathrm{~K}$ and $900 \mathrm{~K}$, in which hydrogen species at around $650 \mathrm{~K}$ has a strong correlation with super-conductivity. In these systems, hydrogen exists as $\mathrm{H}^{-}$or $\mathrm{H}^{\delta-}$. The hydrogen desorption peaks for carbon nanotubes are lower than $\mathrm{C}_{60}$, indicating that the interaction of carbon nanotubes with hydrogen is weaker than that of $\mathrm{C}_{60}$. The temperature region of desorption suggests that the charge transfer occurs hydrogen from $\mathrm{C}_{60}$ and carbon nanotubes.

For OMNT and CMNT, the absorbed amount of hydrogen for CMNT is larger than that for OMNT. As for the both, the basic structure is the same, and the difference of the both is only the presence of end caps. Therefore, this result that CMNT with end caps shows a larger amount of absorption indicates that sites which are composed of end caps are more active for the adsorption and absorp- tion of hydrogen on and in the used OMNT and CMNT in the temperature region above $77 \mathrm{~K} . \mathrm{C}_{60}$ shows the de- sorption of hydrogen at around $300 \mathrm{~K}$.

Figure 2 shows the thermal desorption of hydrogen from carbon blacks. An amorphous type carbon black S3 has sorption states for hydrogen at around $300 \mathrm{~K}$. The sorption state of S3 appeared at $374 \mathrm{~K}$ changed to the higher temperature side by graphitization. However, graphitization causes the creation of the sorption states at around $230 \mathrm{~K}$ by appearance of new electronic states of micro-graphite. Among these carbon blacks, amorphous type carbon black shows the sorption characteristic for hydrogen sorption at around room temperature.

Figure 3 shows the hydrogen desorption from carbon nanohorn. The desorption feature is similar to the graphitized carbon blacks: The sorption states appear at around $130 \mathrm{~K}$ and $500 \mathrm{~K}$. However, the sorption states appeared in the lower temperature side are stronger the than

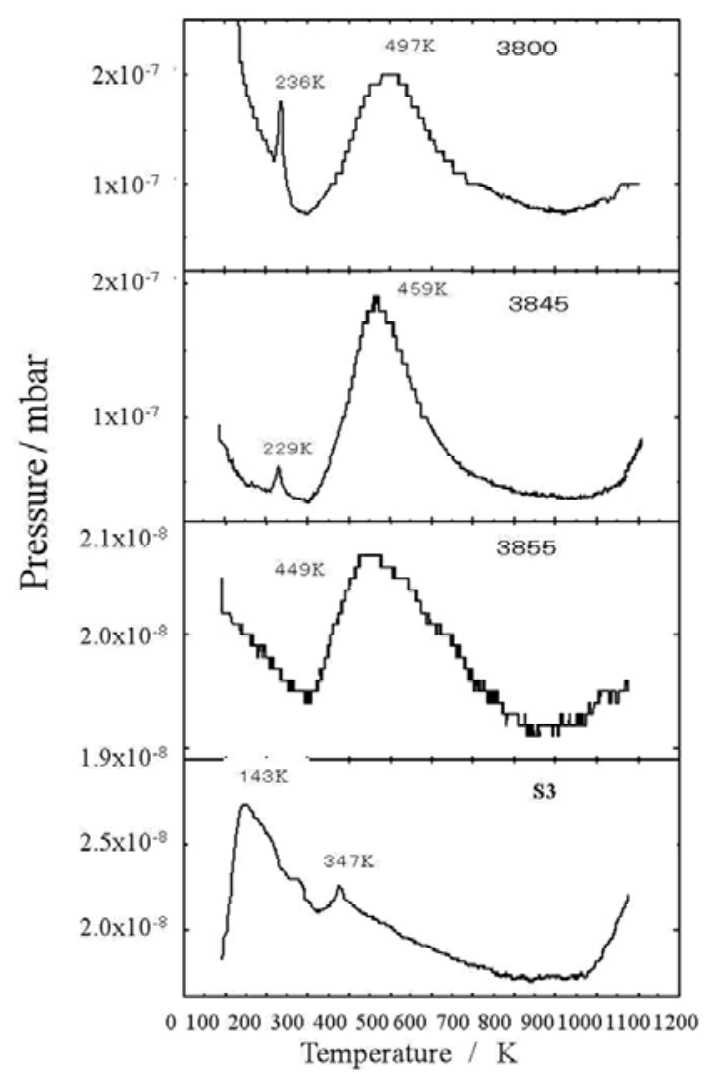

Figure 2. The thermal desorption of hydrogen from carbon blacks.

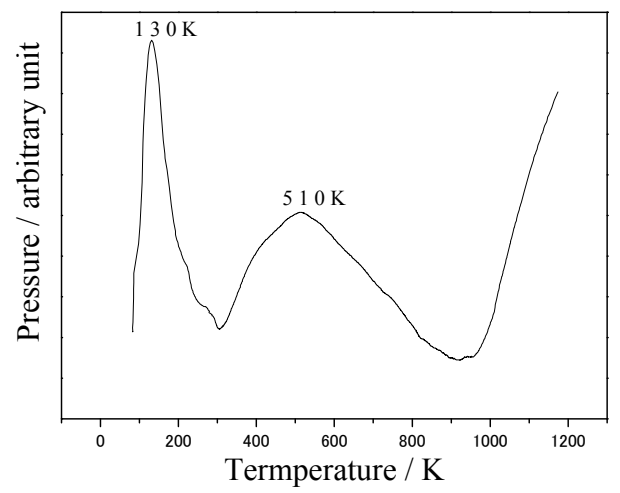

Figure 3. The thermal desorption of hydrogen from carbon nanohorn.

those of graphitized carbon blacks.

\section{Conclusions}

The sorption state at around $300 \mathrm{~K}$ is found in $\mathrm{H}_{2}$ desorption from $\mathrm{C}_{60}$, carbon blacks and carbon nanohorn. These sorption abilities have utility for energy technologies such as fuel cells. By changing the structure and aggregation states of carbons as shown in $\mathrm{C}_{60}$, carbon blacks and carbon nanohorn, it is possible to create the new electronic state and their sorption characteristics for hy- 
drogen sorption at around room temperature.

\section{Acknowledgements}

Authors thank Tokai Carbon Co. for the sample supply of carbon blacks. Authors also thank Dr. T. Yamaguchi of Nagoya University and Professor S. Iijima of Meijo University for the sample supply of carbon nanohorn.

\section{REFERENCES}

[1] K. Ichimura, K. Imaeda and H. Inokuchi, "Characteristic Interaction of $\mathrm{Na}-\mathrm{H}-\mathrm{C}_{60}$ and $\mathrm{C}_{60}$ with Hydrogen and Rare Gases," Molecular Crystals and Liquid Crystals, Vol. 340, No. 1, 2000, pp. 649-654.

[2] C.-W. Jin, K. Ichimura, K. Imaeda and H. Inokuchi, "Interaction of Fullerenes and Carbon Nanotubes with Diatomic Molecules," Synthetic Metals, Vol. 121, No. 1-3, 2001, pp. 1221-1222. doi:10.1016/S0379-6779(00)00868-7

[3] K. Imaeda, H. Inokuchi, K. Ichimura, S, Inoue, S. Nakakita and H. Okamoto, "Hydrogen Interaction in Potassium- $\mathrm{C}_{60}$," Molecular Crystals and Liquid Crystals, Vol. 340, No. 1, 2000, pp.667-670. doi: $10.1080 / 10587250008025544$

[4] K. Imaeda, F. Tian, H. Inokuchi and K. Ichimura, "Three Components Organic Superconductors: Intercalation of
KH into $\mathrm{C}_{60}$," Journal of Solid State Chemistry, Vol. 145, No. 2, 1999, pp. 421-426. doi:10.1006/jssc.1998.8112

[5] K. Imaeda, J. Kröber, C. Nakano, H. Inokuchi and K. Ichimura, "Recovery and Enhancement of Superconducivity in the Sodium-Hydrogen- $\mathrm{C}_{60}$ Ternary System," The Journal of Physical Chemistry B, Vol. 101, No. 48, 1997, pp. 10136-10140. doi:10.1021/jp9714476

[6] K. Imaeda, J. Kröber, H. Inokuchi, Y. Yonehara and K. Ichimura, "Superconductivity in Sodium-Hydrogen- $\mathrm{C}_{60}$ Ternary Compounds," Synthetic Metals, Vol. 85, No. 1-3, 1997, pp. 1575-1576. doi:10.1016/S0379-6779(97)80355-4

[7] K. Imaeda, J. Kröber, H. Inokuchi, Y. Yonehara and K. Ichimura, "Superconductivity in Nah Intercalated $\mathrm{C}_{60}$," Solid State Communications, Vol. 99, No. 7, 1996, pp. 479-482. doi:10.1016/0038-1098(96)00306-7

[8] T. Yamaguchi, S. Bandow and S. Iijima, "Synthesis of Carbon Nanohorn Particles by Simple Pulsed Arc Discharge Ignited between Pre-Heated Carbon Rods," Chemical Physics Letters, Vol. 389, No. 1-3, 2004, pp. 181185. doi:10.1016/j.cplett.2004.03.068

[9] S. Iijima, M. Yudasaka, , R. Yamada, S. Bandow, K. Suenaga, F. Kokai and K. Takahashi, "Nano-Aggregates of Single-Walled Graphitic Carbon Nano-Horns," Chemical Physics Letters, Vol. 309, No. 3-4, 1999, pp. 165-170. doi:10.1016/S0009-2614(99)00642-9 